\title{
TÓPICOS SOBRE A DESUMANIZAÇÃO TECNOLÓGICO-MERCANTIL
}

\author{
Fernando Pereira Marques
}

\begin{abstract}
RESUMO
A espectacularização do poder e do Estado por via dos aparelhos mediáticos, contribui para ocultar a desumanização tecnológico mercantil alimentada pelo sistema económico-financeiro, na atual fase de desenvolvimento do capitalismo. Estes fenómenos marcam a sociedade na sua globalidade e, nomeadamente, o ensino e a cultura que perdem as referências humanísticas para se tornarem instrumentos de reprodução do statu-quo. Mesmo as novas tecnologias da informação e da comunicação que inicialmente se definiam como visando contribuir para a realização dos indivíduos se tornam instrumentos de alienação e de submissão construindo uma meta-realidade. Importa recusar a sobredeterminação da política, da cultura, da educação, da informação e da comunicação pela economia e pela finança fomentando uma nova consciência crítica.
\end{abstract}

\section{PaLAVRas-chave}

Capitalismo; cultura; educação; mercantilização; poder; média

\begin{abstract}
The spectacularization of power and the state using the media machine helps hide the technological and commercial dehumanization fed by the economic and financial system during capitalism's current stage of development. These phenomena mark society as a whole and education and culture in particular, which are losing humanistic references to become instruments for reproducing the status quo. Even new information and communication technologies, which were initially defined as aiming to contribute to individuals' fulfilment, become instruments of alienation and submission by building a meta-reality. It is important to reject the overdetermination of politics, culture, education, information and communication by the economy and finance by encouraging a new critical awareness.
\end{abstract}

\section{PaLAVRAS-Chave}

Capitalism; culture; education; commercialization; power; media

Ameaça-nos um novo crepúsculo da racionalidade. A espectacularização do poder e da política, como já acontecia nos diversos totalitarismos, alimenta-se da manipulação das emoções e dos instintos, em prejuízo da cidadania. Os poderes tornam-se invisíveis, são descentrados e dispersos pelos novos senhores da finança, da economia e dos média que dominam a nível planetário, moldando mentalidades e influenciando comportamentos, em especial no que se refere ao consumo. O Estado fica cada vez mais reduzido à sua encenação mediática e à auto-reprodução de um pessoal político burocratizado 
que, ao contrário do que acontecia noutras fases da democracia representativa, na sua maioria não age em função de projetos ideológicos e estratégias de futuro. Limita-se a veicular para dentro do sistema os interesses das oligarquias dominantes geridos no dia a dia pela tecnoestrutura, interesses que determinam hierarquias, referências culturais, valores, normas e habitus. A mundialização é este estado de coisas no seu apogeu, penetrando todos os interstícios da sociedade e influenciando a vida até aos mais remotos cantos do mundo.

As luzes das lojas luxuosas alimentam a fetichização das marcas nas grandes cidades, mas não conseguem ocultar a agressão à dignidade humana que constitui o contraste entre os objetos que iluminam e a miséria dos que procuram o calor que dessas luzes emana para passar mais uma noite ao ar livre. Estes já não se reduzem aos vagabundos de outrora, são também universitários triturados pelas irracionalidades do ensino e a desresponsabilização do Estado, operários ou mesmo quadros superiores que a brutalidade do reenginnering e da deslocalização mundializada expulsa das empresas, por vezes já numa idade em que se torna difícil recomeçar a vida. É toda uma diversidade de dramas individuais e familiares que a retórica da má consciência assistencialista designa por pudicas siglas: os SDF (sem domicílio fixo) ou os SA (sem abrigo). Aliás, como se vê no nosso país e noutros mais atingidos pela economia política "austeritária", enquanto os mercados e as bolsas se "reanimam" e os dividendos da banca e dos grandes grupos aumentam, está-se a regressar à caridade praticada por instituições religiosas e corações sensíveis, às "sopa dos pobres", aos "bancos da fome" e a outras formas de tentar colmatar as consequências mais escandalosas do desmantelamento dos instrumentos de proteção e da irracionalidade do estádio atual de desenvolvimento do capitalismo.

Os verdadeiros responsáveis pelo descontrolo das dívidas e dos défices, pela recessão, pelo desemprego e por todos os demais fenómenos característicos da conjuntura atual, pretendem, através dos seus agentes políticos, reinstaurar modelos de organização económica, de sociedade e do Estado que permitam concorrer com o capitalismo selvagem dos países emergentes ou, ainda, adotar, adaptando, as formas de exploração desses países e de outras regiões do globo. Estes factos significam uma regressão, em muitos aspetos, ao século XIX ou à primeira metade do século XX, como demonstra a redução, observada nos últimos decénios, da parte do rendimento nacional atribuído ao trabalho'. Regressão justificada com argumentos pseudo-benignos de tipo desenvolvimentista ou orçamentais, nos contextos onde se torna necessário utilizar instrumentos formalmente democráticos de legitimação do poder através da manipulação comunicacional do voto e da opinião pública.

A desumanização tecnológico-mercantil passa também pela destruição da dimensão humanista da cultura e da escola. A cultura esmagada pela imagem, pelo efémero

\footnotetext{
'Thomas Piketty na sua obra fundamental escreve: "no início dos anos 1970, o valor total dos patrimónios - deduzidas as dívidas - situava-se entre dois e três anos e meio de rendimento nacional em todos os países ricos e em todos os continentes. Quarenta anos mais tarde, no início dos anos 2010, os patrimónios privados representam entre quatro e sete anos de rendimento nacional, nos países estudados. A evolução geral não suscita dúvidas: com bolhas ou sem elas, assiste-se efectivamente a um grande regresso do capital privado nos países ricos desde os anos 1970, ou se se quiser à emergência de um novo capitalismo patrimonial". Isto é, observou-se: "um movimento de privatização e de transferência gradual da riqueza pública para riqueza privada desde os anos 1970-1980" (Piketty, 2013, p. 273).
} 
e pelo dinheiro, massifica-se e torna-se, sobretudo, objetos transacionáveis e de consumo. As políticas culturais democratizadoras falharam no plano estrutural porque, secundarizando a educação e o ensino, não conseguiram superar os desvios gerados pelo sistema; limitaram-se a operações de cosmética quanto às desigualdades de acesso das pessoas ao enriquecimento espiritual e ao usufruto do belo e do único. Várias formas de criação niveladas por um "tudo é cultura" tornam-se simples entretenimento, espetáculo, ornamento dos poderes e ilustram a degradação das sociedades contemporâneas neste domínio. Como no passado, e no fundamental, só minorias, social ou educacionalmente privilegiadas, acabam por ter acesso ao conhecimento que liberta e à decifração de linguagens estéticas elaboradas e enriquecidas que o Estado - lato sensu - ou a iniciativa de alguns criadores e instituições privadas promovem, para que se mantenha uma conveniente pátina civilizacional (Pereira, 2016).

Os poderosos têm a possibilidade de em leilões poderem, com maior ou menor discrição, exibir as fabulosas fortunas arrematando obras consagradas para as suas coleções pessoais ou de se dedicarem a outros tipos de ostentação e exibição do status. $O$ Estado, salvaguardada a referida pátina civilizacional, condicionado orçamentalmente por prioridades próprias à fase de financeirização ultraliberal da economia (em termos simples isto significa que, por exemplo, a sustentabilidade da banca prevalece por sobre as outras funções e sectores), passou a gerir o património histórico e artístico segundo critérios mercantis de rendibilidade: monumentos alugam-se como cenários para "animação", a língua contabiliza-se em termos de deve e haver, os museus tornam-se lojas e atrações comerciais. Evidentemente que há uma dimensão económica na produção e nas práticas culturais, mas ela deve ser potenciada através da integração dessa produção e dessas práticas no exercício da cidadania e na procura da realização integral do indivíduo.

Propicia-se aos jovens - e não só - subprodutos esteticamente primários ou espetaculares (talk shows, reality shows, festivais, etc.) com que podem embriagar-se ou entregar-se a comportamentos coletivos exorcizantes das suas angústias e canalizadores das energias que, de outra forma, se poderiam virar contra os poderes instituídos. Ou seja, às massas, à multidão, vende-se entretenimento, vedetas pagas a peso de oiro, jogadores de futebol milionários, mitos construídos pelo marketing, ruído, imagens, numa palavra, espetáculo. Por isto se entendendo a criação de uma meta-realidade que oculta o mundo e a vida.

Do básico ao superior o ensino passou a ser organizado, igualmente, em função da lógica mercantil e das necessidades do sistema económico. Não se procura que cada cidadão contribua com as suas diferentes capacidades e saberes adquiridos para o bem comum, mas que se integre no funcionamento dos mercados e nas dinâmicas de circulação do capital ao serviço de quem de facto decide porque de facto possui. O conceito de rendibilidade é assim estendido ao próprio processo educativo e, por isso, com a introdução de certas reformas, como entre nós a de Bolonha, pretende-se que as crianças e os jovens se limitem a obter competências aplicáveis à reprodução do capitalismo tal qual existe. 
As Humanidades desaparecem, paulatinamente, ou reduzem-se à ínfima expressão nos curricula dos vários graus de ensino; a História, a Filosofia, a Antropologia, a Sociologia, a Geografia, as ciências sociais em geral, são secundarizadas ou direcionadas para a sua aplicação imediata no processo económico; as línguas - "mortas" ou "vivas" - desaparecem sob a língua - o inglês - que, além de ser a da potência ainda liderante, melhor corresponde às necessidades dos diversos discursos técnicos, tecnológicos, mercantis.

Nas universidades - lato sensu - institui-se um controlo burocrático da atividade docente a partir de critérios quantitativos de produção intelectual. Confundindo-se o que é específico à investigação nas áreas das ciências exatas e da Natureza, com o que são as metodologias das ciências sociais e humanas, privilegia-se o número de papers - como se diz - apresentados em conferências e colóquios. Pelo que, sob a pressão das necessidades de financiamento e das avaliações burocráticas, os papers atropelam-se, repetem-se, produzem-se artificialmente; do mesmo modo que se contabiliza, administrativamente, o número de artigos publicados em revistas "científicas". Por consequência, e sempre no que diz respeito às ciências sociais e humanas onde as incidências de tais orientações são porventura mais evidentes, secundariza-se a importância do trabalho em profundidade de que surgem ensaios e livros, assim como o papel, que deveria ser central, da atividade letiva, com a inerente e insubstituível interatividade, relação viva e vivida entre professores e alunos.

Aliás, nas "horas de contacto" - como hoje se chama às aulas - recomenda-se a redução da bibliografia ao mínimo indispensável, privilegiando-se o fracionamento das obras através de fotocópias e a exposição das matérias ("conteúdos", é o termo preferido) recorrendo a powerpoints. Se na universidade do passado, tradicional e conservadora, se cultivava, em grande medida, a passividade dos alunos face à docência ex cathedra, hoje fomenta-se igual passividade perante a esquematização projetada num ecrã e um minimalismo pretensamente didático subvertedor da complexidade.

O objetivo de educar as crianças e os jovens para se realizarem enquanto pessoas capazes de autodeterminação e cidadãos úteis à humanização da polis, é substituído pela sua transformação em unidades destinadas a produzir e a consumir numa sociedade onde se fomenta, como se fossem qualidades, a competição, o egoísmo predador e a injustiça.

O homo consumidor das sociedades desenvolvidas é mantido numa realidade virtual, o que designamos por meta-realidade, devido à ação alienante e conjugada da ideologia e do mercado. Os governos, ao não quererem, ao não ousarem ou ao não poderem contrariar os interesses privados nacionais e transnacionais que os condicionam, obtêm a legitimação de que necessitam em democracia e gerem o statu quo ocultando o que realmente se joga, iludindo o que verdadeiramente interessa ao dia a dia dos cidadãos e ao funcionamento das instituições. A arrogância ideológica do capitalismo triunfante é tão insuportável como a dos que atribuíam à História um sentido que, esmagando o indivíduo, conduziria a uma sociedade terminal perfeita, pois reproduz esse esmagamento sob outras formas de conformismo, de mistificação e de atentados à dignidade humana. 
Não por acaso tendo como principal foco de desenvolvimento e projeção planetária Silicon Valley, na região da San Francisco do Flower Power dos anos 1960, as tecnologias numéricas, a "inteligência artificial", originalmente surgidas como uma "contra-cultura" de afirmação e libertação individual, foram absorvidas inevitavelmente pela lógica mercantil do sistema e vieram sustentar o modelo de capitalismo tecno-liberal a que nos referimos. Modelo que se expande com incrível eficácia influenciando toda a vida em sociedade, os modos de produzir, de consumir, de informar, de comunicar, de conviver, de viver, de participar e de decidir (Sadin, 2016).

Visando a rendibilidade e a produtividade sujeita-se o trabalho (portanto os trabalhadores) a sistemas algorítmicos de controlo impessoal (i.e. deixou de haver um interlocutor direto com o qual estabelecer uma dialética argumentativa e reivindicativa); a pretexto do conforto e do bem estar a autonomia pessoal submete-se à racionalidade numérica veiculada por redes e sistemas; em nome de uma ideia mítica de modernidade, a própria criatividade é crescentemente condicionada pela tecnologia. Delega-se o Sapere aude! kantiano numa instância que, sendo produto da inteligência humana, ganha um poder intrínseco que convém aos novos mecanismos de submissão dos indivíduos.

Como superar este estado de coisas? Toda a mudança social é consequência de dinâmicas direta ou indiretamente provocadas pela ação dos atores e esta ação é fruto da tomada de consciência desses mesmos atores inseridos num determinado contexto. Donde, não sendo solução comportamentos como o dos operários que pretendiam impedir o crescimento da indústria mecânica destruindo as máquinas, resta não só recusar a sobredeterminação da política, da cultura e da educação pela economia e pela finança, mas também pelas tecnologias, pois, como sempre, serão os indivíduos os responsáveis pelo seu próprio destino, por aquilo a que se poderá chamar História. Quando falamos de um capitalismo triunfante referimo-nos ao facto dessa sobredeterminação ser aceite como inevitável. E enquanto assim for, não há política em geral nem políticas em especial, culturais e educativas, que não sejam alimentadoras do statu quo.

\section{REFERÊNCIAS BIBLIOGRÁFICAS}

Marques, F. M. P. (2016). Cultura e Política(s). Lisboa: Âncora Editora.

Piketty, T. (2013). Le capital au XXIe. siècle. Paris: Seuil.

Sadin, É. (2016). La silicolonisation du monde. Paris: Éditions l'Échapée.

\section{NOTA BIOGRÁFICA}

Fernando Pereira Marques (Coruche, 1948), é diplomado pela École des Hautes Études en Sciences Sociales (EHESS) de Paris e Doutor de Estado em Sociologia pela Universidade de Amiens (França), professor catedrático convidado na Universidade Lusófona de Humanidades e Tecnologias (aposentado), onde dirigiu o $2^{\circ}$ Ciclo de Ciência Política, e investigador integrado no Instituto de História Contemporânea da 
Universidade Nova de Lisboa. Entre outros cargos, foi Deputado à Assembleia da República, presidente da Subcomissão Parlamentar de Cultura e membro da delegação portuguesa na Assembleia Parlamentar do Conselho da Europa tendo integrado, entre outras, a Comissão de Cultura e Educação. É autor de várias obras nas áreas do ensaísmo e da investigação e Diretor-Adjunto da revista Finisterra (Diretor Eduardo Lourenço).

E-mail: pereira.marques@sapo.pt

Endereço: Instituto de Historia Contemporânea da Universidade Nova de Lisboa (IHC) - Av. de Berna,26 - 1050-099 Lisboa

* Submetido: 08/08/2017

* Aceite: 29/09/2017 